\title{
Size-Specific Effects of Density on the Growth, Fecundity and Mortality of the Fish Fundulus heteroclitus in an Intertidal Salt Marsh
}

\author{
R. T. Kneib \\ University of Georgia, Marine Institute, Sapelo Island, Georgia 31327, USA
}

\begin{abstract}
Three size classes of Fundulus heteroclitus (L.) (small, 40-50 mm total length; medium, 50-69 $\mathrm{mm}$ TL; large, $\geq 70 \mathrm{~mm}$ TL) were maintained on an intertidal salt marsh in separate enclosures $\left(10 \mathrm{~m}^{2}\right)$ for 10 months at 3 densities $\left(1,2\right.$ and 4 ind $\left.\mathrm{m}^{-2}\right)$. During the final 6 weeks of the experiment (March-April 1979) the effects of density on individual growth as well as mortality and fecunduty of the enclosed populations were assessed. Although fish density and growth were inversely related in all size classes, the growth rate of small $F$. heteroclitus remained positive even after 6 weeks at the highest experimental density. Medium size fish grew when enclosed at densitıes of 1 and 2 ind. $m$ " but not at 4 ind. $\mathrm{m}^{-2}$. The growth of large fish was positive only in cages containing 1 ind. $m^{2}$. Over the range of experimental treatments, fecundity of medium sizc $F$ hotoroclitus exhibited the strongest negative response to high density. However, the gonadosomatic index for large fish was lower than for ether of the other size classes at all experimental densities, suggesting that fecundity of large individuals may be severely impatred even below the lowest density $\left(1 \mathrm{ind} . \mathrm{m}^{2}\right)$ used $\mathrm{n}$ the experiment. Density and fish losses (mortahty + escape) were directly related only in the small and large fish size classes. After 6 weeks at a density of $4 \mathrm{~m}^{-2}, 77 \%$ of the small fish and $60 \%$ of the large fish were lost compared to only $32 \%$ of the medium size individuals. Escape accounted for an estimated $13.2 \%$ of all losses and was independent of density. Totai losses reflected a density-dependent trend in small and large fish mortality.
\end{abstract}

\section{INTRODUCTION}

Early field investigations of competitive interactions (e. g. Andrewartha and Birch, 1954; MacArthur, 1958) were largely observational. Recently there has been a proliferation of rigorous field experimentation demonstrating the role of interspecific competitive interactions in determining the local abundance and distribution of organisms (Connell, 1961; Dayton, 1971; Wilbur, 1972; Menge, 1976; Hairston, 1980). Although intraspecific competition was the focus of many classical laboratory experiments (e.g. Nicholson, 1933; Gause, 1934; Park, 1954), it has not been studied under experimental field conditions as intensively as has interspecific competition. Eisenberg (1966) found that food additions dramatically increased the fecundity of enclosed populations of the snail Lymnaea elodes. Stiven and Hunter (1976) showed that the growth rate of caged Littorina irrorata (marsh periwinkle) was reduced at high densities in a salt marsh habitat. In another intertidal snail study, Underwood (1976) found that different age classes of Nerita atramentosa exhibited alternative responses to density. At high density, juvenile and adult grow:h rates decreased; only adult mortality increased. These experiments and others conducted in aquatic habitats (Frank, 1965; Behrens, 1971; Stiven and Kuenzler, 1979) used either gastropod or bivalve molluscs. Vertebrates are usually unsuitable for use in controlled experiments in the field because their high motility dictates cage sizes of impractical proportions. Although there have been some studies with fish, few have dealt with size (age)-specific effects of density. Beverton and Holt (1957) implied that of all the density-dependent responses studied in fish populations, the relationship between density and growth was the best known. Backiel and LeCren (1978) cited numerous examples of increases in fish growth rates in response to decreased density under field conditions. Weatherley (1972) stated that because of individual growth plasticity in fish, general relationships 
between growth and density could be misleading or unrealistic, and work in this area should consider differential effects due to fish size. Most controlled experiments dealing with fish growth have been performed on young age classes, presumably because of their normally rapid growth rate and the short time interval required to produce results. Edwards et al. (1970) altered the densities of both young plaice and the bivalve mollusc Tellina (the siphons of Tellina tenuis were eaten by the fish) in large outdoor, flow-through seawater tanks and found that fish at high density relative to their food supply showed reduced growth.

Recent studies of the production dynamics of the common mummichog Fundulus heteroclitus (L.) have suggested that this abundant cyprinodontid fish has an important role in energy transfers within the salt marsh (Valiela et al., 1977; Meredith and Lotrich, 1979) Although mummichog production estimates in these studies were presented on a per $\mathrm{m}^{2}$ basis, there were no direct measurements of the marsh area required to produce the observed fish growth rates.

The present work was part of an investigation to test the effects of Fundulus heteroclitus size and density on the benthic infaunal community of a North Carolina salt marsh (Kneib, 1980). Kneib (1980) showed that infaunal densities were affected more by fish size than fish density. In the statistical analysis of those data, the effects of $F$. heteroclitus density alone were obscured because small and large mummichogs had opposite effects on the densities of most small benthic invertebrates. However, the effect of fish size on invertebrate abundance patterns was intensified at certain fish densities. High infaunal numbers occurred in response to increasing the density of large $F$. heteroclitus. The lowest infaunal densities occurred when only small mummichogs were present or when all fish were excluded. Predation by the grass shrimp Palaemonetes pugio Holthuis, was presumed to be the reason for these results because the shrimp are known to reduce infaunal densities (Bell and Coull, 1978) and there was evidence indicating that only large $F$. heteroclitus could control shrimp densities in the experimental enclosures. Regardless of the exact mechanism, changes in size-specific mummichog densities altered the abundance of potential prey species. It follows that competition should act through the altered prey densities to affect parameters that control predator ( $F$. heteroclitus) population dynamics.

Mummichogs follow the rising tide onto the salt marsh where they feed on a variety of benthic and epibenthic invertebrates (Butner and Brattström, 1960; Schmelz, 1964; Kneib and Stiven, 1978; Weisberg et al., 1981). The fish are frequently stranded by the ebbing tide in shallow pools and water-filled depressions on the marsh surface, where they are exposed to rigorous physical conditions. Fundulus heteroclitus is remarkably well adapted for survival in a wide range of temperature and salinity regimes and under oxygen deficient conditions which could result from being stranded at high densities in shallow marsh pools (Lewis, 1970; Griffith, 1974; Mitton and Koehn, 1976; Targett, 1978, 1979) These characteristics make mummichogs excellent subjects for field experiments in the intertidal salt marsh where the fish can be maintained in cages containing artificial pools simulating a physical environment to which they are well adapted and normally encounter

The purpose of the present investigation was to assess the size-specific effects of density on individual growth, fecundity and mortality in enclosed field populations of Fundulus heteroclitus.

\section{MATERIALS AND METHODS}

\section{Study Area}

The experiments were conducted in the intertidal zone of Tar Landing Marsh located on Bogue Banks at $34^{\circ} 42^{\prime} \mathrm{N}, 76^{\circ} 42^{\prime} \mathrm{W}$ in the vicinity of Beaufort, North Carolina, USA. The site was within the boundaries of Fort Macon State Park which provided protection from human disturbance. The dominant vegetation in the study area is the cord grass Spartina alterniflora. There is little freshwater input to the marsh and salinity remains around 30-36 ppt. Tidal range at the study site is $\sim 85 \mathrm{~cm}$. A detailed description of the area has been reported elsewhere (Kneib and Stiven, 1978).

\section{Experimental Enclosures and Treatments}

All experiments were conducted in cages constructed of fiberglas screening ( $\sim 1.5 \mathrm{~mm}$ mesh) and measuring $3.16 \mathrm{~m}$ square $\left(10 \mathrm{~m}^{2}\right) \times 1 \mathrm{~m}$ high. The 27 cages were arranged in 3 equal rows parallel to the tide line. Enclosures were contiguous within a row The bottom edges of the enclosures were buried $15-20 \mathrm{~cm}$ in the marsh sediment and the sides were stapled to $(1.5 \mathrm{~m} \times 5 \mathrm{~cm} \times 5 \mathrm{~cm})$ treated wooden posts. Two pits $(50 \times 50 \times 50 \mathrm{~cm})$ dug at the low end of each cage retained water and provided a low tide refuge for the experimental fish.

Experimental enclosures received either small (40-50 mm TL), medium (50-69 $\mathrm{mm}$ TL) or large ( $\geq 70$ mm TL) Fundulus heteroclitus at densities of 10, 20 or 40 individuals per cage $\left(1,2\right.$ or 4 ind. $\mathrm{m}^{-2}$, respectively). There were 3 replicates of each treatment combination. Since sexual differences in growth and mortality occur in F. heteroclitus (Kneib and Stiven, 1978), 
equal numbers of males and females were added to each enclosure. Half of the fish in each cage were marked by the subcutaneous injection of Liquitex ${ }^{(\beta)}$ acrylic paint, a technique previously used on mummichogs by Lotrich and Meredith (1974). Four colors (cadmium red medium, cobalt blue, permanent green light and cadmium yellow light) and 2 injection locations (dorsal and ventral caudal peduncle) yielded a sufficient number of distinct combinations to individually mark half of the fish in any cage. The marks were easily distinguishable after at least 3 months and as previously reported by Lotrich and Meredith (1974) produced very low marking mortality which in the present investigation allowed a high percentage recovery (usually $80-100 \%$ in low density cages).

Fish infrequently crossed cage partitions. However, a marked fish from one treatment cage was occasionally recaptured in an adjacent cage, sometimes resulting in an enclosure with 2 identically marked fish. The stray was invariably identified by its sex or size and returned to the appropriate treatment.

Enclosures were monitored periodically to assure maintenance of the treatment levels. Fish were removed from the enclosures by placing minnow traps in each enclosure pit for 30 min at low tide. Each trap was baited with a freshly collected mussel (Geukensia

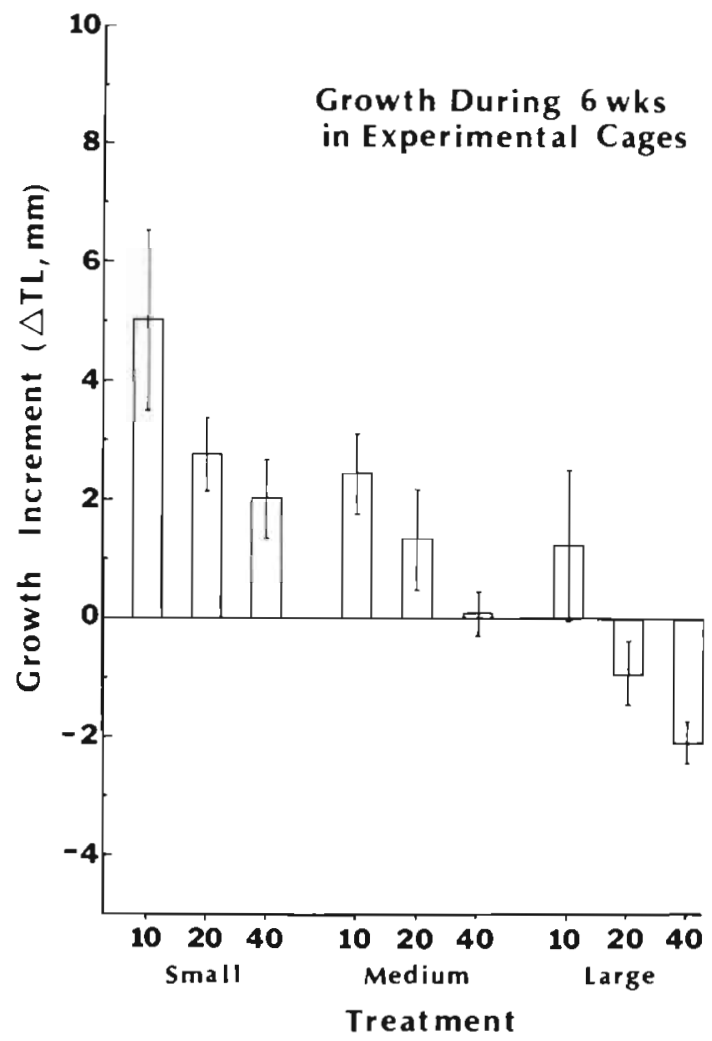

Fig. 1 Fundulus heteroclitus. Mean change in total length $(\mathrm{mm}) \pm 2 \mathrm{SE}$ of marked individuals after 6 weeks at each combination of fish size and density demissa), the shell of which was cracked slightly to attract fish into the trap but to prevent them from feeding on the bait. All fish removed from the cages were measured (total length, TL), counted and returned to the pits. Fundulus heteroclitus of appropriate size were added when necessary, to compensate for losses due to mortality and/or escape. Although the fish densities were maintained for 10 months from the initiation of the experiment in June 1978, a full complement of marked fish was not maintained until March 1979, at which time monitoring occurred in a sequence as follows: (1) In mid-March 1979, fish were removed from all cages and freshly captured $F$. heteroclitus were measured, marked and added in the appropriate size-density combinations. (2) After 2 weeks, the enclosures were sampled, the fish measured and losses compensated with additions of both marked and unmarked fish. (3) Three weeks later (mid-April 1979), the enclosures were again sampled, but all losses, whether from marked or unmarked experimental populations, were replaced by fresh unmarked F. heteroclitus. (4) At the end of April 1979, all fish were removed from the enclosures and preserved in $10 \%$ seawater formalin.

\section{Growth Determinations}

Density effects on growth were determined by 2 methods. The 6 week incremental increase in length (TL, $\mathrm{mm}$ ) achieved by individual marked fish was compared in an ANOVA with fish density and size as main effects. Fish size was included as a factor because growth in Fundulus heteroclitus as in other fish, slows with age (Beverton and Holt, 1957; Kneib, 1976).

A second approach compared mean dry weights of marked fish from each experimental density in an analysis of covariance. The analysis included fish that had been marked both 4 and 6 weeks before the termination of the experiment. After the gut contents were removed, experimental fish were dried at $60^{\circ} \mathrm{C}$ for 1 week to obtain a relatively stable dry weight. Gonads were dried and weighed separately but added to the body weight to yield the total weight used in all calculations. The sexes were treated separately because length-weight relationships in Fundulus heteroclitus differ by sex (Kneib and Stiven, 1978). A logarithmic transformation was applied to the length and weight data to linearize the relationship.

\section{Fecundity Determinations}

It was not possible to evaluate fecundity directly by counting the number of eggs produced per female 
mummichog at each density because multiple spawnings were possible. However, 2 indirect assessments of fecundity relative to fish density were made for each fish size class. The first compared the proportion of females carrying ripe oocytes (defined in Kneib and Stiven, 1978) at the end of the experiment. Density effects were compared separately for each fish size class in three $2 \times 3$ contingency tables from which chisquare values were calculated. In the second approach, an ANOVA was performed on dry gonad weight as a percent of total dry body weight (gonadosomatic index, GSI). Because the data were expressed as proportions, an $\arcsin \sqrt{x}$ transformation was applied prior to statistical analysis. All marked fish subjected to the experimental treatments for 4-6 weeks were included.

\section{Mortality}

The proportions of marked fish missing from each treatment (after 2 and 6 weeks) were analyzed in contingency tables using chi-square to assess the relative importance of density on the losses of fish in each size class. Some losses were due to escape, complicating the direct estimate of density dependent mortality However, escape losses were estimable from the number of marked fish that were assigned to a particular cage but were recaptured in an adjacent cage. Although most enclosures shared 2 sides, those on the ends of rows shared only 1 . Assuming that escape was equally likely through any of the 4 sides of a cage, the number of actual escapes from an enclosure was the same as the number of fish recaptured from the enclosures adjoining on both sides or $1.5 \times$ the recovered fish for enclosure occupying terminal positions in a row.

\section{RESULTS}

\section{Growth}

Both fish size and fish density were factors determining incremental growth as measured by change in total length (Fig. 1). An ANOVA indicated that statistical differences in growth due to fish size (F, P $<0.001)$ and fish density (F, P $<0.001)$ were highly significant. There was no significant size $\mathrm{x}$ density interaction ( $\mathrm{F}$, $P>0.05)$. Note that the mean change in length was negative for large fish held at densities of 20 and 40 fish per cage.

The mean weight for a fish of a given length was also affected by density. This evaluation was conducted as an analysis of covariance on fish weight with fish length and fish density as covariates. The first step in the analysis was to compare the slopes of the weight on
Table 1 Fundulus heteroclitus. Results from analysis of covariance showing calculated mean dry weights (mg), adjusted for length, at each experimental fish density. Table values: antilog. of means from transformed $(\ln x)$ data

\begin{tabular}{|lccc|}
\hline Sex & \multicolumn{4}{c|}{ Fish density (ind. cage ${ }^{-1}$ ) } \\
& 10 & 20 & 40 \\
\hline Males & 851.7 & 849.1 & 798.9 \\
Females & 856.1 & 814.9 & 756.4 \\
\hline
\end{tabular}

Table 2. Fundulus heteroclitus. Numbers of marked females with and without ripe oocytes after 6 weeks at 3 density treatments. Chi-square values testing for the effect of density on the proportions of ripe females in each size class are shown

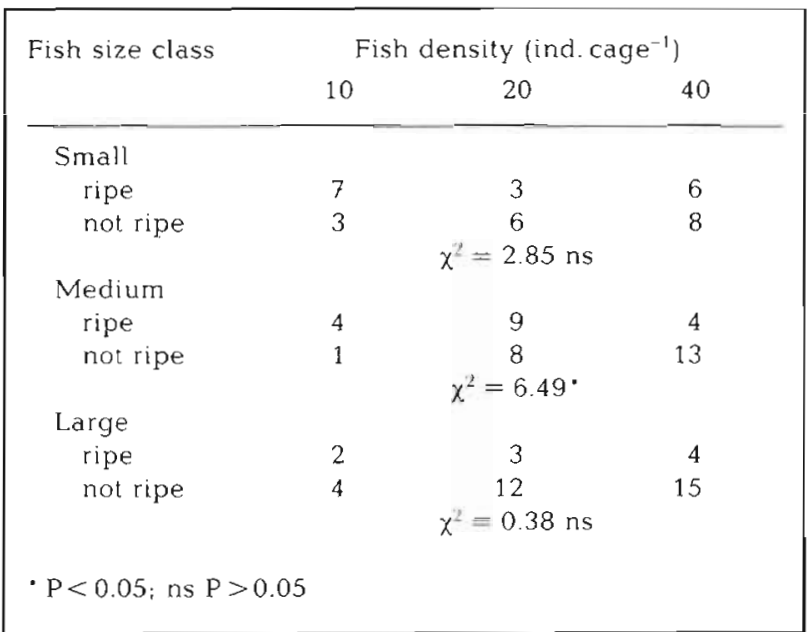

length regression lines for fish held at each of the 3 densities. This was done by performing an ANOVA on the weight data with length and density as the independent variables. The interaction term, length $x$ density, was then used as a test for differences in slopes. There was no statistical evidence for any differences ( $F, P>0.05)$ in the slopes among density groups for either sex.

Having satisfied the equality of slopes assumption, the mean dry weights adjusted for length were calculated for both sexes at each experimental density (Table 1). The effect of density on mean weight was statistically significant in both males $(F, P<0.01)$ and females $(F, P<0.001)$. However, increased density had a greater effect on the weight of females.

\section{Fecundity}

Effects of the 3 fish densities on the proportion of marked female mummichogs carrying ripe oocytes were compared in contingency tables for each fish size class (Table 2). There was no statistical evidence that 


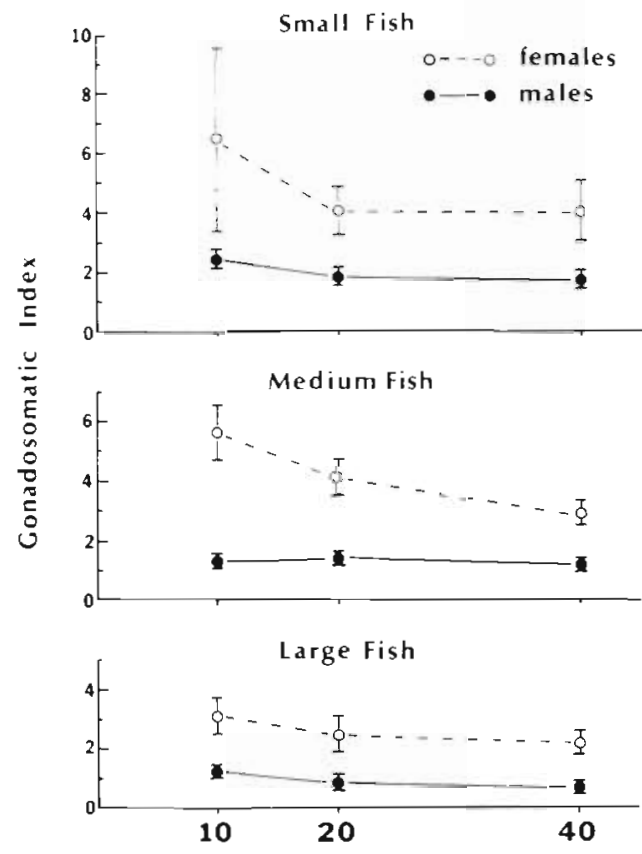

Fish Density (no. per cage)

Fig. 2. Fundulus heteroclitus. Effect of densily on gonadosomatic index of males and females. Results are presented for each fish size class separately. Points are mean GSI $\pm 2 \mathrm{SE}$

density affected the percentage of either small or large fish carrying ripe ova, but the proportion of ripe females in the medium size class decreased significantly with density

Density also affected gonadosomatic index (GSI) (Fig. 2). A 2-factor ANOVA indicated a significant density effect on the GSI of both medium $(F, P<0.001)$ and large $(F, P<0.05)$ fish However, there were no significant differences in the GSI of small fish due to density $(F, P>0.05)$. Of course, sex was a highly significant factor $(F, P<0.001)$ affecting the GSI of all fish size classes. There was a significant density $x$ sex interaction $(F, P<0.05)$ only in medium size fish, reflecting the proportionally greater effect of density on female GSI in this size class (Fig. 2). The highest variance was associated with mean GSI values of small fish. Although large fish of both sexes responded to increased density by decreasing GSI, the response was relatively small (Fig. 2).

\section{Mortality}

The proportions of marked fish lost from each density treatment after 2 and 6 weeks were compared with separate chi-square tests for each fish size class. Losses (Fig. 3) were significantly density dependent for small fish at both 2 and 6 weeks $\left(\chi^{2}, P<0.001\right)$.

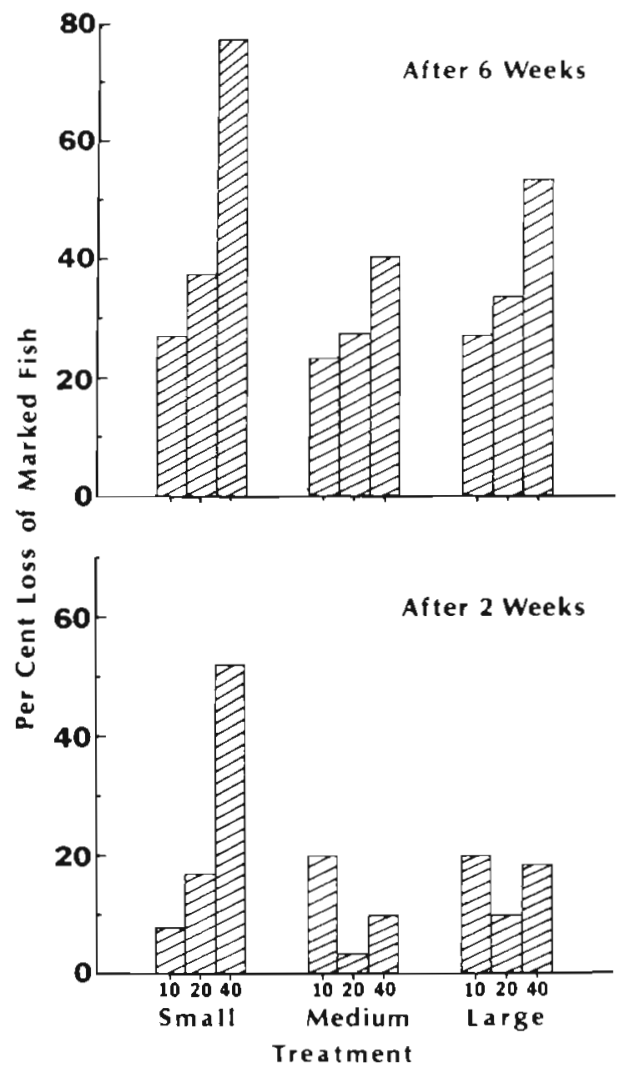

Fig. 3. Fundulus heteroclitus. Percent of marked individuals lost from experimental enclosures after 2 and 6 weeks at the indirated treatment comblnations of fush stze and density. Half of the fish in each demaity tredment were malked and each treatment was replicated 3 times. Thereforo, density treatments of 10,20 and 40 individuals per cage were represented by 15,30 and $60 \mathrm{marked}$ individuals, respectively

There was no detectable pattern in the losses of medium $\left(\chi^{2}, P=0.154\right)$ or large $\left(\chi^{2}, P=0.723\right)$ fish at 2 weeks, but at 6 weeks there was a significant trend in the losses of large fish with increasing density $\left(\chi^{2}\right.$, $\mathrm{P}=0.047$ ). There continued to be no statistical evi-

Table 3. Fundulus heteroclitus. Estimates of escape Iosses from each of the expermental treatments. Table values: numbers of marked fich estimated to have escaped. Values in parentheses: percentages of total losses of marked fish attributable to escape

\begin{tabular}{|ccccc|}
\hline $\begin{array}{c}\text { Fish donsity } \\
\text { (ind.coge })\end{array}$ & \multicolumn{3}{c|}{ Fish size class } & Total \\
\hline 10 & 1 & - & - & \\
& $(25.0)$ & & 5 & 1 \\
20 & 3 & - & $(7.1)$ \\
40 & $(25.0)$ & & $(50.0)$ & $(26.7)$ \\
& 12 & 5 & - & 17 \\
Total & $(14.6)$ & $(19.2)$ & & $(11.1)$ \\
& 16 & 5 & 5 & 26 \\
& $(16.3)$ & $(12.8)$ & $(8.3)$ & $(13.2)$ \\
\hline
\end{tabular}


dence for a similar tendency in medium fish $\left(\chi^{2}, \mathrm{P}=\right.$ 0.452 ).

Estimates of the number of marked fish that escaped from the cages (Table 3 ) indicated that escape losses made a relatively insignificant contribution to the trend in total losses $13.2 \%$ of all losses during this study were estimated to have escaped.) Therefore, the density-dependent trends in total losses (Fig. 3) can be assumed to reflect density-dependent trends in mortality.

\section{DISCUSSION}

\section{Density-Dependent Growth}

Growth, as measured by change in length, was shown to be inversely related to density in Fundulus heteroclitus. Although absolute changes in length were greatest for the smallest fish, all size classes showed growth reductions with density. Large fish at densities of 20 and 40 per cage exhibited negative absolute growth, resulting in losses of up to $4 \mathrm{~mm}$ TL per fish in a 6 week period. It is not likely that these results were due to size-specific measurement error because the number of fish exhibiting negative growth, as well as the magnitude of the length changes, increased with fish density regardless of fish size. After 6 weeks the percentages of large fish exhibiting negative changes in length were: $27.3,50.0$ and 100.0 at densities of 10,20 and 40 fish per cage, respectively. Similarly, the percentages were 0, 13.6, 33.3 for medium fish and $0,0,7.1$ for small fish. Fin damage, which could cause inaccurate measurements of total length, was not a problem even at high density Length losses are known to occur in other fish species but being limited by the vertebral column are usually ignored as a response measurement in favor of weight changes which are of greater magnitude (Ursin, 1979). In the present study, analyses of differences in mean dry weight verified the length increment findings that reductions in growth due to increased densities affected each size class in the same manner A comparison of the mean dry weights (adjusted for length) showed a significant inverse relationship between weight and density. Again, confirming the growth in length results.

The causes of growth inhibition at high density may be quite varied and species-dependent. The possibilities range from growth-inhibiting chemicals (e. g) Pfuderer et al., 1974) to behavior (Magnuson, 1962) and the effects of resource overutilization (Weatherley, 1972). Edwards et al. (1970) conducted experiments with 0 -group plaice in Jarge tanks. Manipulating densities of both the fish and their food supply (Tellina tenuis), the investigators found that food limitation and not crowding was responsible for the observed decreased growth rate at high fish densities. This is probably the case in the present study of mummichog responses to density. All Fundulus heteroclitus size classes responded to increased density with decreased growth. Samples of benthic invertebrates from each enclosure combined with fish gut content analysis suggested that $F$. heteroclitus at high density ( 4 ind. $\mathrm{m}^{2}$ ) reduced the size of particular prey populations (Kneib, 1980). The prey species most affected was dependent on the fish size treatment (Kneib and Stiven, in preparation). Perhaps due to habitat complexity (Vince et al., 1976), large $F$, heteroclitus could not feed heavily on the small invertebrate species that were preferred by small fish. In enclosures containing only small fish, the densities of small invertebrates were reduced, probably due to predation by small $F$. heteroclitus and the presence of grass shrimp Palaemonetes pugio (Bell and Coull, 1978). Small fish were unable to prey effectively on the large grass shrimp. However, gut content analyses indicated that the shrimp were a preferred food of large $F$ heteroclitus in experimental enclosures. Thus, large fish probably controlled the density of grass shrimp, allowing the rapid increase of small infaunal invertebrates which could have been utilized by small F. heteroclitus. Each fish size class was subjected to 3 constant density levels of the same size fish, and no experiments were conducted with mixed size classes. However, the available data suggest that the presence of large $F$. heteroclitus may benefit small mummichogs perhaps through the control of decapod competitors.

\section{The Effect of Density on Fecundity}

The 2 approaches used in the present study to detect density-related changes in size-specific fecundity of Fundulus heteroclitus produced similar results. There was an inverse relationship between density and the proportion of medium-size females containing ripe oocytes. The same relationship held for the gonadosomatic index (GSI) Small fish did not show statistically significant differences in fecundity measures due to density However, an effect may have been masked by the high variability expected from young fish entering their first reproductive episode (Fig. 2). The effect of age on fecundity in fishes is, in general, viewed as an uncertain and inconsistent relationship (Bagenal, 1978; Wootton, 1979). There is some observational evidence that age of maturation may be delayed under low food conditions (McFadden et al., 1965). However, de Vlaming (1971) found that starvation had no effect on the initiation of the reproductive 
cycle in an estuarine goby (Gillichthys mirabilis), but could cause gonad regression. Although age is not considered a reliable determinant of fecundity, some measure of fish size is generally accepted as related to the number of ova produced. However, normal environmental variability distorts the relationship (Nikolskii, 1969). Although the largest fish produce the greatest number of eggs, their contribution to total population fecundity is often small because the population usually comprises relatively few large individuals (Weatherley, 1972). Egg quality (i e. fat and protein content) is usually highest in the medium size fish that make up most of the reproductive population (Nikolskii, 1969). Medium size $F$. heteroclitus were shown to contribute most to population fecundity in the Tar Landing area (Kneib and Stiven, 1978). The fecundity of this size class was also most affected by density in the present study. Large fish also showed an inverse relationship between density and fecundity (Fig. 2), but it was not as strong as in the medium size class. In fact, the mean GSI of large fish was smaller than for either of the other size classes. Mummichogs are multiple spawners (Foster, 1967) and as Wootton (1979) pointed out, GSI may be a misleading index of potential annual fecundity in fish that spawn more than once in a season. Although collections for the present study were made in the spring when most of the population experiences a reproductive peak, larger mummichogs may spawn later in the season, perhaps explaining their lower GSI. However, large fish grew only slightly at the lowest experimental density (1 ind. $\left.m^{2}\right)$ and therefore, a more likely explanation is that they may not have had sufficient energy reserves to invest in reproduction.

Several other studies have shown an inverse relationship between fish density and fecundity. Bagenal (1978) cites several examples from both field observations and controlled experiments. As with the relationship between fish growth and density, there have been several hypotheses advanced concerning densityrelated mechanisms causing reductions in fedundity Warren (1973) presented evidence for a chemical factor that operated in crowded laboratory conditions. However, in field situations it is generally agreed that food limitation affects fish size which in turn affects fecundity (Nikolskii, 1962). Wootton (1979) considered food availability as the most important environmental determinant of fish fecundity. This opinion is supported by several field observational studies (McFadden et al., 1965; Wydoski and Cooper, 1966; Leggett and Power, 1969) and laboratory experiments (Scott, 1962; Hester, 1964; de Vlaming, 1971; Wootton, 1977). The manner in which reduced fecundity occurs in the absence of adequate food resources may vary with fish species. The guppy Lebistes reticulatus responded to decreased food by reducing the number but not the size of young (Hester, 1964) Brown trout Salmo trutta from infertile streams were shown by McFadden et al (1965) to produce fewer eggs than trout of the same size from fertile streams. Scott (1962) showed that the number of atretic ova increased in starved rainbow trout Salmo gairdneri.

Mummichogs in the Tar Landing marsh have been shown to contain an often large but highly variable number of degenerating ova (Kneib, 1976), perhaps reflecting individual variation in condition due to nutritional state. In multiple spawners, like Fundulus heteroclitus, the number of spawnings as well as total egg production may decrease with reduced food supply (Wootton, 1977). However, there are no reliable estimates of the number of times $F$. heteroclitus may spawn in a single season.

In nature, density effects may also occur at the egg stage just after spawning. Mummichogs are known to eat their own eggs (Chidester, 1916; Schmelz, 1964; Able and Castagna, 1975) and probably newly hatched fry. At high density, the effects of decreased food resources would probably result in an even higher rate of cannibalism, especially if protective refuges for eggs (Able and Castagna, 1975) and/or fry (Taylor et al., 1977) were limited.

Regardless of the actual mechanism, reduced reproductive success in Fundulus heteroclitus at high density would have important consequences for the population size structure, since the effects of a single weak year class would be reflected in the population for several years. Changes in the survival or fecundity of the medium size class of $F$. heteroclitus would be expected to produce the most dramatic effects on the future population structure.

\section{Density-Dependent Mortality}

Although the reproductive success (or failure) of one generation may affect the intensity of intraspecific competition in the next generation, mortality has an immediate influence on current competitive interactions. In the present investigation, losses of small and large Fundulus heteroclitus were significantly higher in cages maintained at 4 ind. $\mathrm{m}^{-2}$ than at lower densities. Although escape losses accounted for $13.2 \%$ of the total losses, there was no relationship between density and escapes. Therefore, the density-dependent trends observed in total losses (Fig. 3) reflect the effect of mortality. The effect of escape losses was only to amplify the density-dependent mortality trend. Losses at densities of 10 and 20 individuals per cage were not significantly different within or among size classes, 
falling in the range of $25-35 \%$ after 6 weeks. In the same time period, the highest density ( 40 per cage) resulted in losses of up to $77 \%$. The lowest losses (24-32\%) were suffered by medium size fish. This agrees with field estimates of $F$. heteroclitus mortality trends (Valiela et al., 1977; Kneib and Stiven, 1978).

In general, there is a two-sided literature dealing with the effects of density on mortality in fishes. For every example suggesting density-dependent mortality, there is another that shows either no evidence of increased mortality with density or an inverse relationship (Backiel and LeCren, 1978). Beverton and Holt (1957) suggested that there was little evidence for density-dependent mortality in natural populations of adult fish. Nikolskii (1969) also contended that densities high enough to affect a critical resource like food supply may result in mortality of very young fish. Older fish would be afferted only indirectly. That is, a decreased food supply may cause fish to seek food more actively, making them more susceptible to predation. Nikolskii also suggested that fish in a poor nutritional state may more easily succumb to disease and parasites. Adult fish are more likely to respond to decreased food supply not by dying but by losing weight. The growth and mortality responses of large mummichogs supported this hypothesis early in the present experiment, but continued high density resulted in a significant increase in mortality $(60 \%$ at 4 ind. $\mathrm{m}^{2}$ compared to $29.4 \%$ at 1 ind. $\left.\mathrm{m}^{2}\right)$ after 6 weeks.

Although distinct density-dependent mortality occurred in the present investigation, it may not be a strong influence in natural situations for 2 reasons. First, only the highest experimental density ( 4 ind. $\mathrm{m}^{-2}$ ) produced significantly increased mortality. It is unlikely that mummichogs would attain sustained marsh densities this high and may normally respond to high density by emigrating Therefore, the observed mortality may be a caging effect (sensu Krebs et al., 1973). Second, the food supply in the enclosures was diminished by maintaining the density-size class treatments in them for ten months prior to the mortality measurements. In a sense, the cages were preconditioned against the survival of each size class. Small crustaceans (the primary food of small fish) attained high densities in large fish cages while larger crustaceans (taken primarily by large fish) were abundant in small fish enclosures (Kneib, 1980). Algae and fouling organisms, a potential food source for the enclosed fish and a common problem in subtidal caging experiments, did not grow on the cage walls in the present study. The lack of fouling organisms may be related to the position of the experiment in the mid to high intertidal zone and grazing by the abundant marsh periwinkle Littorina irrorata.
Considering the combined effects of density on growth, fecundity and mortality, medium-size fish responded least to density and seemed most tolerant of crowded conditions. Small fish survived and grew at densities of 1 and 2 per $\mathrm{m}^{2}$ of marsh surface, but experienced heavy mortality losses at higher densities. Large fish required at least $1 \mathrm{~m}^{2}$ of marsh to maintain a positive growth rate. At higher densities, large mummichogs responded first by exhibiting negative growth followed, at the highest experimental density $\left(4 \mathrm{~m}^{-2}\right)$, by high mortality over an extended period ( 6 weeks). The density tolerance of medium size fish may be related to an ability to utilize a wider range of prey sizes than either of the other fish size classes. Under the experimental conditions, medium fish may not have experienced the same effective food shortages as the other 2 fish sizes

Acknowledgements. I wish to thank N. G. Hairston. E. J Kuenzler, C. H. Peterson, S. R. Reice and especially A. E. Stiven for many helpful suggestions and comments on an earlier draft of this manuscript. The paper in its present form benefited greatly from the thoughtful and constructive criticisms and comments of J. P. Schubauer, S. B. Weisberg and T E. Targett. Space and equipment was kindly provided by the faculty and staff of the University of North Carolina Marine Institute. Cooperation by the North Carolina State Parks Service and the staff at Fort Macon State Park was most appreciated. Financid support was provided by NSF grant DEB 76 80443 to A. E. Stiven and S. R. Reice and by the University of North Carolina Curriculum in Ecology. This paper is contribution no. 436 of the University of Georgla Marine Institute

\section{LITERATURE CITED}

Able, K. W., Castagna, M. (1975). Aspects of an undescribed reproductive behavior in Fundulus heteroclitus (Pisces: Cyprinodontidae) from Virginia. Chesapeake Sci. 16: $282-284$

Andrewartha, H. G., Birch, L. C. (1954). The distribution and abundance of animals, University Chicago Press, Chicago

Backiel, T., LeCren, E. D. (1978). Some density relationships for fish population parameters. In: Gerking, S. D. (ed.) Ecology of freshwater fish production. John Wiley and Sons, New York, pp. 279-302

Bagenal, T. B. (1978). Aspects of fish fecundity. In: Gerking, S. D. (ed.) Ecology of treshwater fish production. John Wiley and Sons, New York, pp. 75-101

Behrens, S. (1971). The distribution and abundance of the intertidal prosobranch Littorina scutulata (Gould, 1899) and L. sitkana (Philippi, 1845). M. S. thesis, University British Columbia

Bell, S. S., Coull, B. C. (1978). Field evidence that shrimp predation regulates meiofauna. Oecologia 35: 141-148

Beverton, R. J. N., Holt, S. J. (1957). On the dynamics of exploited fish populations. Fishery Invest., Lond. 19: $1-533$

Butner, A., Brattström, B. H. (1960). Local movements in Menidia and Fundulus. Copeia 1960: 139-141

Chidester, F. E. (1916). A biological study of the more important of the fish enemies of the salt marsh mosquitoes. N. J. Agricultural Experiment Station Bull. 300:1-16 
Connell, J. H. (1961). Effects of competition, predation by Thais lapillus, and other factors on natural populations of the barnacle Balanus balanoides. Ecol. Monogr 31: 61-104

Dayton, P. K. (1971). Competition, disturbance and community organization: the provision and subsequent utilization of space in a rocky intertidal community. Ecol. Monogr. 41: 351-389

de Vlaming, $V$ L. (1971). The effect of food deprivation and salinity changes on reproductive function in the estuarine gobicid fish Gillichthys mirabilis. Biol. Bull. mar. biol Lab., Woods Hole 141: 458-471

Edwards, R. R. C., Steele, J. H., Trevellion, A. (1970). The ecology of 0 -group plaice and common dabs in Loch Ewe. III. Predator-prey experiments with plaice. J. exp. mar. Biol. Ecol. 4: 156-173

Eisenberg, R. M. (1966). The regulation of density in a natural population of the pond snail, Lymnaea elodes. Ecology 47: 889-906

Foster, N. R. (1967). Comparative studies on the biology of killifishes (Pisces, Cyprinodontidae). Ph. D. dissertation, Cornell University, Ithaca, New York

Frank, P. W. (1965). The biodemography of an intertidal snail population. Ecology 46: 831-844

Gause, G. F. (1934). The struggle for existence, Williams and Wilkins, Baltimore

Griffith, R. W. (1974). Environment and salinity tolerance in the genus Fundulus. Copeia 1974: 319-331

Hairston, N. G. (1980). Evolution under interspecific competition: Field experiment on terrestrial salamanders. Evolution, Lawrence, Ks 34: 409-420

Hester, F. J. (1964). Effects of food supply on fecundity of the female guppy Lebistes reticulatus. J. Fish. Res. Bd Can. 21: $757-764$

Kneib, R. T. (1976). Feeding, reproduction, growth and movements of killifishes on a North Carolina salt marsh. M. A. thesis, University of North Carolina, Chapel Hill, North Carolina

Kneib, R. T. (1980). The responses of a soft-sediment intertidal community to experimental manipulations of the population size structure and density of a predator, Fundulus heteroclitus (L.). Ph. D. dissertation, University of North Carolina, Chapel Hill, North Carolina

Kneib, R. T., Stiven, A. E. (1978). Growth, reproduction and feeding of Fundulus heteroclitus (L.) on a North Carolina salt marsh. J. exp. mar Biol. Ecol. 31. 121-140

Krebs, C. J., Gaines, M. S., Keller, B. C., Myers, J. H., Tamarin, R. H. (1973). Population cycles in small rodents. Science, Washington, D. C. 179: 35-41

Leggett, W C., Power, G. (1969). Differences between two populations of landlocked Atlantic salmon (Salmo salar) in Newfoundland. J. Fish. Res. Bd Can. 26: 1585-1596

Lewis, W. M. Jr. (1970). Morphological adaptions of cyprinodontids for inhabiting oxygen deficient water. Copeia 1970: 319-327

Lotrich, V A., Meredith, W. H. (1974). A technique and the effectiveness of various colors for subcutaneous marking of fish. Trans. Am. Fish. Soc. 103: 140-142

MacArthur, R. H. (1958). Population ecology of some warblers of northeastern coniferous forests. Ecology 39: 599-619

Magnuson, J. J. (1962). An analysis of aggressive behavior, growth and competition for food and space in medaka (Oryzias latipes [Pisces, Cyprinodontidae]). Can. J. Zool. 40: 313-363

McFadden, J. T., Cooper, E. L., Anderson, J. K. (1965). Some effects of environment on egg production in brown trout (Salmo trutta). Limnol. Oceanogr. 10: 88-95
Menge, B. A. (1976). Organization of the New England rocky intertidal community: Role of predation, competition and environmental heterogeneity. Ecol. Monogr. 46: 355-393

Meredith, W. H., Lotrich, V. A. (1979). Production dynamics of a tidal creek population of Fundulus heteroclitus. (Linnaeus). Estuar. coast. mar. Sci. 8: 99-118

Mitton, J. B., Koehn, R. K. (1976). Morphological adaptatıon to thermal stress in a marine fish, Fundulus heterochtus. Biol. Bull. mar biol. Lab., Woods tole 151: 548-559

Nicholson, A. J. (19.33). The balance of animal populations. $J$. Anim. Ecol. 2: 132-178

Nikolskii, G. V (1962). On some adaptations to the regulation of population density in fish species with different types of stock structure. In: LcCren, E. D., Holdgate, $W$ W (eds.) The exploitation of natural anmal populations. Symposium Britısh Ecol. Soc., Blackwell, Oxford, pp. 265-282

Nikolskii, G. V (1969). Theory of fish population dynamics as the biological background for rational exploitation and management of fishery resources, Oliver and Boyd. Edinburgh

Park, $\tau$ (1954). Experimental studies of interspecies compet. tion 11. Phystol. Zool. 27: 177-238

Pfuderer, P., Willams, P., Francis, A. A. (1974). A partial purification of the crowding factor from Carassus auratus and Cyprınus Carpı. J. exp. Zool. 197: 37.5-382

Schmelz, G. S. (1964). A natural history of the mummichog, Fundulus heteroclitus, in Canary Creek Marsh. M. S thesis, Unversity Delaware, Newark, Delaware

Scott, D. P. (1962). Effect of food quantity on fecundity of ralnbow trout Salmo gairdneri. J. Fish. Res. Bd Can. 19: $715-731$

Stiven, A. E., Hunter, J. T (1976). Growth and mortality of Littorina irrorata Say in three North Carolna Salt marshes. Chesapeake Sci. 17: 168-176

Stiven, A. E., Kuenzler, E. J. (1979). The response of two salt marsh molluscs, Littorina irrorata and Geukensia demissa, to field manipulations of density and Spartina litter Ecol. Monogr 49: 151-171

Targett, T E. (1978). Respiratory metabolism of temperature acclimated Fundulus heteroclitus (L.): Zones of compensatıon and dependence. J. exp. mar. Biol. Ecol. 32: 197-206

Targett, T E. (1979). The effect of temperature and body size on digestive effictency in Fundulus heteroclitus (L.). J. exp. Mar Biol. Ecol. 38: 179-186

Taylor, M. H., DiMichelle, L., Leach, G. J. (1977). Egg stranding in the life cycle of the mummichog. Fundulus heteroclitus. Copeia 1977: 397-399

Underwood, A. J. (1976). Food competition between ageclasses in the intertidal neritacean Nerita atramentosa Reeve (Gastropoda: Prosobranchia). J exp. mar Biol. Ecol. 23: 145-1.54

Ursin, E. (1979). Principles of growth in fishes. In: Miller, P. J. (ed.) Fish phenology: Anabolic adaptiveness in teleosts Academic Press, London, pp. 63-87

Valiela, I., Wright, J. E., Teal, J. M., Volkmann, S. B. (1977) Growth, production and energy transformations in the salt-marsh killifish Fundulus heteroclitus. Mar Biol. 40: $135-144$

Vince, S., Valiela, I, Backus, N., Teal, J. M. (1976). Predation by the salt marsh killifish Fundulus heteroclitus in relation to prey size and habitat structure: consequences for prey distribution and abundance. J. exp. mar Biol. Ecol. 23: $255-266$

Warren, E. W (1973). Modification of the response to high density conditions in the guppy poecilia reticulata (Peters). J. Fish. Biol. 5: 737-757 
Weatherley, A. H. (1972). Growth and ecology of fish populations. Academic Press, London

Weisberg, S. B., Whalen, R., Lotrich, V A. (1981). Tidal and diumal influence on food consumption of a salt marsh killıfish Fundulus heteroclitus. Mar. Biol. 61: 243-246

Wilbur, H. M. (1972). Competition, predation and the structure of the Ambystoma-Rana sylvatica communty. Ecology $53: 3-21$

Wootton, R. J (1977). Effect of food limitation during the breeding season on the size, body components and egg production of female sticklebacks (Gasterosteus aculeatus). J. Anım. Ecol. 46: 823-834

Wootton, R. J. (1979). Energy costs of egg production and environmental delerminants of fecundity in teleost fishes. In: Miller, P. J. (ed.) Fish phenology: Anabolic adaptiveness in teleosts. Academic Press, London, pp. 133-159

Wydoski, R. S., Cooper, E. L. (1966). Maturation and fecundity of brook trout from infertıle streams. J. Fish. Res. Bd Can. 23: 623-649 